\title{
LA CIRCULARIDAD DIALOGICA RESTAURATIVA DE LA ANGUSTIA EN EL ESPACIO DE MUTUALIDAD RELACIONAL
}

\author{
Raúl Gutiérrez Sebastián ${ }^{1}$ \\ Zaragoza, España
}

En mayo de 2017 tuve la oportunidad de supervisar un caso clínico con Howard Bacal, tras una clase que impartió a propósito de las aportaciones de la teoría de la especificidad a la psicoterapia y la responsividad óptima. En dicha supervisión intercambiamos impresiones sobre cómo pensar acerca de la experiencia intersubjetiva de la angustia. Intervenciones y opiniones que me invitaron a continuar reflexionando en torno a algunas cuestiones relacionadas con la angustia, así como con las posiciones del sujeto y el analista en relación a la experiencia subjetiva e intersubjetiva de la misma. El presente artículo pretende desarrollar algunas de las reflexiones que han ido surgiendo a lo largo de este tiempo, las cuales van tejiendo un pensar sobre la angustia en términos relacionales e intersubjetivos, como una experiencia emocional metacomunicativa, donde procesos circulares dialógicos restaurativos, intra e interpersonales, favorecen la integración en el Self de la experiencia de angustia y de experiencias emocionales invalidadas que pueden subyacer a la angustia. También pretendo introducir algunas conclusiones relacionadas con la regulación emocional desde la mutualidad relacional en relación a la integración de aspectos disociados de la experiencia temprana invalidada.

Palabras clave: Circularidad Dialógica Restaurativa, angustia, experiencia emocional invalidada, ambiente invalidante.

In May 2017, I had the opportunity to supervise a clinical case with Howard Bacal, after a lecture he gave on the contributions of the theory of specificity to psychotherapy and optimal responsiveness. During this supervision, we exchange impressions on how to consider the intersubjective experience of anguish. Interventions and opinions induced me to continue reflecting on issues related to anguish, as well as the positions of the subject and the analyst in relation to the subjective and intersubjective experience of the same. This article aims to develop some of the reflections that have emerged over this period, which develops a way of thinking about anguish in relational and intersubjective terms, as a metacommunicative emotional experience, where circular dialogical restorative processes, intra and interpersonal, favor the integration in the Self of the experience of anguish and of invalidated emotional experiences that may underlay the anguish. I also intend to introduce some conclusions related to the emotional regulation from the relational mutuality in relation to the integration of dissociated aspects of the invalidated early experience.

Key Words: Circularity Restorative Dialogue, anguish, invalidated emotional experience, invalidating environment.

\section{English Title: THE CIRCULARITY RESTORATIVE DIALOGUE OF THE ANGUISH WITHIN RELATIONAL MUTUALITY}

\section{Cita bibliográfica / Reference citation:}

Gutiérrez Sebastián, R. (2018). La circularidad dialógica restaurativa de la angustia en el espacio de mutualidad relacional. Clínica e Investigación Relacional, 12 (1): 141-162. [ISSN 1988-2939]

[Recuperado de www.ceir.info ] DOI: 10.21110/19882939.2018.120111

\footnotetext{
${ }^{1}$ Psicólogo de FAIM. Psicoterapeuta FEAP. Terapeuta Familiar FEATF. Email: raulgs@cop.es 


\section{DE LA CIRCULARIDAD ENDOGENA Y EXOGENA}

La relación terapéutica, entre profesional y paciente, se puede considerar como "un marco para crecer, construir intersubjetividad, donde las multiplicidades del Self se expresan, validan su expresión, se confrontan con las posibilidades de cambio que genera la intersubjetividad del vínculo terapéutico, abierto a la improvisación y al encuentro con lo inesperado" (Ávila Espada 2015, p.396).

Esta relación se basa en la circularidad de los estados del Self entre dos o más sujetos que se sirven de la propia relación para crecer y madurar.

El concepto de circularidad ya ha sido ampliamente desarrollado y discutido en el ámbito de la terapia familiar sistémica, desde Bateson (1972, 1979), también los teóricos de la comunicación (Watzlawick, Beavin y Jackson, 1981) y el grupo de Milán (Palazzoli Selvini et al., 1980), quienes introducen y desarrollan el concepto de las entrevistas circulares como medio para conducir cambios en la dinámica relacional familiar.

Me sirvo del concepto de circularidad, reconociendo que no es una aportación propia ni novedosa, pero advirtiendo un uso particular de dicho concepto, que amplía su significado y lo lleva al campo de las relaciones y del espacio intersubjetivo, necesario para el desarrollo del sujeto en relación con figuras significativas a lo largo de toda la vida, más allá de su significado y concepción sistémica.

Es por ello que me gustaría comenzar esta disertación sobre la angustia en el campo de la mutualidad relacional, desarrollando el sentido de circularidad y aportando algunas claves que nos sirvan para comprender el motivo de tales reflexiones.

Los modelos de pensamiento actuales han evolucionado de los propios modelos explicativos causales y lineales, hasta fundamentar teorías en modelos no lineales, o también llamados "circulares", que revelan las relaciones desde la mutualidad y la bidireccionalidad de la influencia recíproca de las personas implicadas en el espacio interactivo e interpersonal.

Esta misma evolución la podemos observar en el desarrollo de la teoría del apego, la cual se ha ido distanciando de las posturas psicoanalíticas más tradicionales, fundamentadas en la pulsión, para ir reseñando la relevancia del vínculo (Bowlby, 1969; Marrone, 2001) que implica la interacción bidireccional y de reciprocidad en la configuración del apego y su influencia en el desarrollo de funciones estructurales de la persona.

La propia teoría de la intersubjetividad, plantea que:

...el desarrollo de sentido de realidad del niño se produce, principalmente, a través de la sintonía emocional validante por parte del entorno, una sintonía suministrada a través de un completo 
espectro de experiencias afectivamente intensas, positivas y negativas. (Stolorow y Atwood, 1992, p. 64).

Respecto al vínculo de apego, cabe señalar que la relación que co-construimos entre paciente y analista pretende posibilitar un lugar donde depositar transferencialmente determinadas experiencias, posiblemente invalidadas hasta ese momento, en el espacio de mutualidad y bidireccionalidad relacional, que va a permitir circular a modo transferencialcontratransferencial el contenido que subyace al malestar vivenciado y, progresivamente, favorecerá un escenario de auto-regulación desde la activación de procesos reflexivos (Fonagy y Bateman, 2016) y empáticos - en el sentido kohutiano del término, (Cf. Kohut, 2002) - entre los partícipes.

La circularidad se fundamenta en dos procesos básicos, a saber:

Circularidad interna o endógena. La cual estaría determinada por la interrelación de los diversos estados del Self, las experiencias afectivo-emocionales, la capacidad de mentalizar, los modelos operativos internos, así como los estilos de apego y vinculación, aspectos que convergen entre sí, constituyendo la personalidad del individuo.

Circularidad externa o exógena. Habida cuenta de todo lo anterior, cobra sentido en tanto que determina la manera en que confluyen los aspectos personales del sujeto y del otro de la interacción, en un espacio de mutualidad relacional configurada en torno a los patrones relacionales y el conocimiento relacional implícito de cada participante, desde donde se construye/constituye, la matriz relacional.

Un aspecto a señalar en este sentido es el concepto de "matriz interactiva" (Greenberg, 1995), la cual hace referencia al setting relacional en el cual se resignifica la experiencia compartida y que emerge de la propia circularidad interna y externa de los participantes de la interacción

Ambas circularidades, endógena y exógena, con figuras significativas, permiten explorar posibilidades relacionales dado que se relacionan entre ellas y con las de los demás, configurando procesos transaccionales entre las características personales de los propios participantes, así como entre ellos mismos, lo que permite significar la experiencia y formularla, integrando así la misma en los diversos estados del Self (Bromberg, 2017).

Por tanto, el sentido en el que propongo el concepto de Circularidad Dialógica Restaurativa se trata de un proceso bidireccional de autorregulación intrapersonal, desde procesos interpersonales y viceversa. Diálogos internos e interpersonales que cohabitan en el sujeto y entre él y su contexto relacional y de mutualidad interpersonal, los cuales dan coherencia y continuidad al desarrollo del Self. 


\section{LA ANGUSTIA COMO METACOMUNICACIÓN DE LA EXPERIENCIA EMOCIONAL INVALIDADA EN EL CAMPO RELACIONAL}

¿Debe ser el objetivo ahondar en las dificultades de las personas, para que sean conscientes del contenido que subyace a su malestar? Personalmente considero necesario conocer a qué responde dicho malestar y qué experiencias relacionales promovieron la adaptación en el pasado $y$, de alguna manera, resulta disfuncional en la actualidad, para poder construir alternativas relacionales que beneficien "experiencias emocionales correctoras" (Alexander y French, 1946) que, a su vez, favorezcan procesos madurativos del desarrollo del Self y de la integración de aspectos del mismo previamente disociados.

Juan José Martínez (2017), comenta que la angustia es una emoción positiva, aunque su reacción y la vivencia de la misma sea desagradable. No podría estar más de acuerdo con el autor. Su obra relacionada con "El enigma de la angustia" ha sido un punto de partida para desarrollar una mirada a la angustia que me permita comprender la misma en términos relacionales, aunque me tome el permiso de darle una vuelta al concepto propuesto para comprender la función positiva de la angustia, aspecto que espero poder clarificar a lo largo del presente texto.

En este sentido, tanto Juan José Martínez como Jorge Tió, Lluis Mauri y Pilar Raventós (2014), desarrollan un concepto de la angustia como experiencia emocional que acompaña el desarrollo y la maduración. Tanto Martínez (2017) -desde la comprensión de la angustia de crecimiento como Tió et al. (2014), matizan y amplían la compresión del fenómeno de la angustia con la dimensión "claustro-agorafóbica".

Tomando como referencia dichas aportaciones, me gustaría profundizar en la función de la angustia como emoción en el marco del proceso madurativo de todo sujeto, ya sea infante, adolescente o adulto y apuntalar, desde ahí, su función positiva para el sujeto.

En relación a la experiencia emocional, Leslie Greenberg y Sandra C. Paivio (2000), proponen una mirada a la experiencia emocional, similar a la concepción nominal de Antonio Damasio (1995), pero proponiendo una conceptualización diferente y una lectura, a mi entender, más operativa. Dichos autores comprenden las emociones como un programa motor no aprendido e innato, al que se añaden algunas estrategias cognitivas, que en conjunto tienen como finalidad la conducción de la vida, reconociendo así mismo la función adaptativa para el sujeto en su contexto relacional y cultural.

Greenberg (2000) propone una revisión de las emociones diferenciando entre emociones primarias, primarias desadaptativas, secundarias e instrumentales. 
Esta clasificación respondería a la integración de las mismas durante fases tempranas del desarrollo, dependiendo de la respuesta que el entorno dio a la experiencia emocional compartida con figuras de cuidado significativas.

Destaco aquí la importancia que el ambiente facilitador (Winnicott, 1979) tiene para la integración de la experiencia afectiva o, por el contrario, la relevancia del ambiente invalidante (Linehan, 2003) en la posible fragmentación del Self, por disociación del afecto y la vivencia del trauma evolutivo que puede conllevar tales experiencias. Entendiendo por "ambiente invalidante" aquel que responde erráticamente, por defecto o por exceso, a la experiencia subjetiva compartida del sujeto durante largos periodos de tiempo del desarrollo madurativo.

Para Greenberg (2000), al igual que Damasio (1995), las "emociones primarias" son respuestas adaptativas y funcionales a un suceso/acontecimiento del mundo exterior, las cuales nos ayudan a satisfacer una necesidad básica insatisfecha. Greenberg introduce el concepto de "emociones primarias desadaptativas", como aquellas emociones emergentes y adaptativas al estímulo externo competente que las evoca, pero expresadas de manera desregulada. En este sentido, considero que dicha desregulación es el resultado madurativo de una respuesta inadecuada, prolongada en el tiempo, por parte del entorno temprano del sujeto ante la experiencia emocional del mismo. Un ejemplo sería la vivencia compartida del miedo en un contexto familiar/social invalidante, donde experimentar dicha emoción no está bien visto y el sujeto la vive como algo deshonesto e impropio (cuando una figura cuidadora significativa puede responder ante la misma con connotaciones negativas similares a "Sentir miedo es de débiles"). Por este motivo el sujeto tenderá a reprimir la emoción en el contexto situacional que la estimula y no tendrá la oportunidad de regularla e ir adaptándola, mostrando la misma ante el retorno del contenido reprimido, de manera desregulada y con angustia, dada la preocupación ante la respuesta del entorno a la experiencia emocional vivida.

Este mismo autor, habla también de las "emociones secundarias", las cuales considera como: "respuesta a emociones primarias comparadas con un ideal moral", "una capa protectora de la identidad". "lo que se expresa como una emoción, incluye la reacción de la persona con dicha emoción y como la persona se relaciona con ella...cuando las personas sienten que no aceptan una emoción, o se sienten amenazados por ella, lo que experimentan no es la emoción en sí misma, sino la consecuencia de no poder experimentar dicha emoción" (Greenberg. y Paivio, 2000, p.71). Esta experiencia guarda relación con la incapacidad de experimentar determinadas emociones dado el profundo temor a "no ser", a la fragmentación del Self, incluso a que se dé lugar a la aniquilación del sí mismo.

Supongamos ahora que la respuesta del entorno, lejos de ser descalificativa, como en el ejemplo antes expuesto, es más profundamente invalidante, y se muestra desconfirmadora de la 
experiencia emocional compartida del sujeto (algo así como "los miembros de esta familia no lloran"). Esta afirmación, aunque aparentemente invalide la experiencia de la misma manera que la anterior, si miramos con detenimiento, es más profundamente invasiva, agresiva e invalidante, pues llorar me roba mi ser, aniquila al "Self" y como "no puedo no ser", despliego mecanismos defensivos disociativos que permitan poder integrar la experiencia del "no ser" en el Self.

Adviértase la distinción entre emociones que han sido descalificadas (como las emociones que Greenberg denomina "primarias desadaptativas"), que son reprimidas, y las que han sido desconfirmadas (las denominadas "secundarias"), que se disocian de la experiencia para salvaguardar la integridad del Self. Esto responde a la consideración de que no se van a mostrar en el espacio relacional con la misma intensidad y formalidad, aunque ambas experiencias muestren la angustia en el espacio de mutualidad relacional.

En este sentido, Philip Bromberg (2017) comenta que:

La represión como defensa, reacciona ante la ansiedad (un afecto negativo pero regulativo que señala un conflicto intrapsíquico desagradable, pero tolerable). La disociación como defensa es sensible al trauma, inundación producida por afectos no regulados que dominan la mente, amenazando la estabilidad de la identidad y, algunas veces, la cordura. Conflictos intrapsíquicos que llegan a ser experiencias insoportables, no solo displacenteras. (p. 120).

Robert Stolorow y George Atwood (1992) proponen:

Dos modelos distintos del trauma psíquico. En uno, el trauma era el producto de un estado afectivo insoportable y abrumador; en otro, era causado por la emergencia de una idea inaceptable. (p. 97)

Emergen así respuestas alternativas y diferenciadas a la experiencia emocional, del miedo o la tristeza u otras emociones consideradas "desagradables", donde la angustia va a jugar un papel fundamental, pues la hipótesis que defiendo es que, en estos casos, la angustia metacomunica la invalidación de la experiencia emocional, un contenido reprimido o disociado del Self, con el propósito y función de salvaguardar la integridad del Self, siendo este el vértice que da sentido a la función positiva de la angustia.

Donde afirma Juan José Martinez (2017) que:

La angustia no aparece en el repertorio de reacciones emocionales habituales durante el desarrollo de un niño. Y no aparece porque a nuestros padres, ese modelo operativo interno tampoco se lo dijeron, y de manera transgeneracional, se fue trasladando, o bien la ausencia de ese concepto o, lo que es peor, una idea negativa, dramática y trágica a la vez, de la angustia" (p. 144) 
Lo que propongo es la consideración de que eso mismo sucede, no solamente con la angustia, sino con toda experiencia emocional, llamémosla, "desagradable", como puede ser el miedo, la ira o la tristeza. Por este motivo, ante la desregulación de estas otras emociones - primigenias, básicas y adaptativas - que no han sido registradas e integradas en el repertorio de modelos operativos internos o en el marco del conocimiento relacional implícito, emerge la angustia como respuesta ante la dificultad para experimentarlas, regularlas y expresarlas. Esto explicaría por qué la angustia no se experimenta hasta etapas posteriores del ciclo vital.

Dada la imposibilidad, o dificultad, de hacerse eco de determinadas experiencias emocionales invalidadas en estadios tempranos del desarrollo, lo que propongo es considerar la funcionalidad positiva de la angustia en el espacio relacional como el eje que vincula y vehicula la experiencia emocional invalidada en el pasado, con el contexto situacional interpersonal que la evoca en el aquí y ahora. Por ello, al igual que otros autores, considero la angustia como una experiencia emocional propia, pero matizando que debe ser comprendida como una emoción secundaria que aparece como resultado de la invalidación previa de otra emoción. Emociones que, cultural e históricamente, son ciertamente invalidadas en nuestra sociedad por aquellas figuras significativas que nos acompañan en procesos tempranos del desarrollo, y que responden erráticamente, por exceso o por defecto, a la experiencia emocional del infante.

En este sentido Kierkegaard (citado en Martínez Ibáñez, 2017, p.26) distingue entre miedo y angustia: "Desde la perspectiva que entiende el miedo como una emoción intensamente desagradable, que está vinculada a un objeto real, mientras que la angustia es vivenciada como sin objeto, indeterminada y flotante". Me detengo en esta definición para argumentar mi exposición de la comprensión de la angustia como emoción que metacomunica otra experiencia emocional privada, no compartida en el espacio interpersonal, la cual no responde a un estímulo externo competente sino a la experiencia de invalidación de la experiencia emocional privada no compartida.

En el contexto terapéutico, es en la propia relación entre los participantes donde el paciente va a depositar aquellos aspectos sufrientes $y$, de alguna manera, desadaptativos, que le motivan a proponerse un cambio, dado que es precisamente en la relación transferencial donde el paciente organiza la afectividad que le permite proyectar los roles de las figuras significativas de su pasado en el analista, en el aquí y el ahora (Cf. Khan, 1991). La relación le permite poner de relieve sus dificultades y explorar las alternativas adaptativas de crecimiento.

En la relación transferencial-contratransferencial, el analista debe cumplir principalmente dos funciones: sostener (Winnicott, 1960) y contener (Bion, 1962). Dicho en otras palabras, validar aquel contenido relacionado con experiencias vitales que fueron invalidadas en etapas tempranas del desarrollo y contener aquellos aspectos que se manifiestan de manera 
desregulada (Estalayo, Rodríguez y Romero, 2009), como es a través de la angustia. Ambos aspectos, considero, forman parte del encuadre en el establecimiento de la relación terapéutica para promover una relación segura:

En este sentido, construir un vínculo, que contenga y valide, nos brinda la posibilidad de trabajar... aquellos momentos donde el menor encuentra estímulos evocadores de aquellos contenidos emocionales invalidados y/o desregulados, los cuales van a depositarse en la relación con el profesional.

Precisamente estos momentos son oportunidades de contener aquel comportamiento desregulado, expresión de un contenido emocional privado no compartido y, seguramente, invalidado, además de favorecer un escenario sobre el que construir una experiencia emocional validante que signifique lo que acontece tras la expresión de malestar vivenciado. (Estalayo, Rodríguez y Gutiérrez, 2016, p. 38)

Así mismo, a través de la contención y la validación, aseguramos la relación, dado que: "El hacer que el campo intersubjetivo sea cada vez más seguro, permite la exploración, la indagación, el juego, y el desarrollo de una organización psicológica nueva o revisada" (Orange, Atwood y Stolorow, 2012, p. 71).

Por todas estas razones parece necesario comprender el origen y la emergencia de la angustia, así como su relación con la invalidación de la experiencia emocional temprana, como una desregulación o disfunción de la experiencia de la misma y la subsiguiente vivencia de angustia, por la incapacidad de registrar de manera integrada en el Self determinadas experiencias emocionales.

Solo de ese modo estaremos en condiciones de dar respuesta a las necesidades relacionales del paciente en correspondencia con la experiencia de angustia vivida, ofreciendo en el campo intersubjetivo la suficiente contención, confrontación, validación y facilitación necesarias para integrar la experiencia, hasta ahora invalidada, desde el propio marco relacional e intersubjetivo que co-construimos ambos participes del escenario interpersonal.

\section{DESREGULACIÓN DE LA EXPERIENCIA EMOCIONAL, FRAGMENTACIÓN DEL SELF Y LA EMERGENCIA DE LA ANGUSTIA}

Podemos preguntarnos qué relación guarda todo lo anteriormente expuesto con la clínica del paciente y la expresión del malestar, a través de la angustia, en el plano relacional.

Bromberg (2017) plantea la cuestión sobre el impacto que el trauma evolutivo temprano concepto afín al denominado "acumulativo" (Khan, 1963) -, así como la disociación asociada al 
trauma, pueden ejercer sobre la capacidad del sujeto para la regulación interpersonal de los afectos.

"En el desarrollo temprano, un adulto provee gran parte de la modulación de los estados del niño, especialmente en momentos de alteración emocional o en la transición entre estados y esta intervención posibilita la auto-regulación"

Y continúa "La emoción es al principio regulada externamente por el cuidador primario, pero en el curso de la infancia se va incrementando la regulación interna como resultado del desarrollo neurofisiológico" (Bromberg, 2017, p. 23).

En un ambiente facilitador, el cuidador primario provee las posibilidades necesarias para que el infante pueda integrar las experiencias interpersonales, afectivas y emocionales, que emergen de la relación a lo largo de la infancia, pero ¿Qué ocurre en un ambiente invalidante o inhibidor que no provee de tales posibilidades?, según este autor "el cuidador primario induce estados traumáticos de afecto negativo persistente en el niño. Este cuidador es inaccesible y reacciona de forma inapropiada o rechaza las expresiones emocionales y de estrés de su hijo. En vez de modular, induce niveles extremos de estimulación y excitación" (Bromberg, 2017, p. 28). Dicha experiencia ejercerá efectos traumáticos a través de la hiperactivación y la disociación.

Es por ello que considero la emergencia de la angustia como una expresión de dificultad, incluso imposibilidad, de experimentar determinados afectos adaptativos en ciertas situaciones contextuales y relacionales. La angustia sería una respuesta de hiperactivación de patrones neurofisiológicos que reflejan la incapacidad del sujeto para percibir y procesar determinados estímulos externos e integrarlos como internos. Por ello, es imprescindible que el terapeuta se comprometa en sintonizar afectivamente con el paciente, y así favorecer, en un espacio intersubjetivo seguro, la posibilidad de experimentar, en ese equilibrio inestable, la sobrecarga afectiva que conlleva la emergencia del trauma evolutivo en el aquí y el ahora.

Al aludir a la "capacidad de sintonizar afectivamente", conviene señalar que lo hago en el sentido de los teóricos de la intersubjetividad, como: "una sintonía suministrada a través de un completo espectro de experiencias afectivamente intensas, positivas y negativas" (Stolorow y Atwood, 1992, p.64); siempre dentro de una relación co-construida, fundamentada en la confianza básica. Esta sintonía da seguridad al sujeto en la relación terapéutica y le permite experimentar, desde las bases previamente comentadas de contención y validación, las propias vivencias afectivas.

Tras la fragmentación del Self, o la aparición y puesta en escena del Falso Self (Winnicott, 1979), cuya configuración centrípeta busca esconder y proteger al verdadero Self (Cf. Abello y Liberman, 2011, p. 159), o - lo que es lo mismo - la disociación del Self (Bromberg, 2017), emerge una respuesta ansiógena o angustiosa que responde a la imposibilidad del sujeto de "no sentir". 
En su ambiente temprano, inhibidor e invalidante, no se le ofrecieron respuestas suficientemente sensibles que favorecieran la integración de la experiencia para un desarrollo saludable, por lo que el sujeto tuvo la necesidad de recurrir a respuestas alternativas, adaptativas para la supervivencia.

Como se propone desde la teoría de la comunicación humana, "no se puede no comunicar" (Watzlawic, Beavin y Jackson, 1981, p.52), entendiendo la comunicación como pautas de interacción, y las emociones como pautas de comunicación relacionales (intra e interpersonal). Me sirvo de dicho axioma para proponer que "tampoco se puede no sentir". Retomemos entonces la función positiva que Juan José Martínez introduce en su obra "el enigma de la angustia" (2017), que, a mi entender, tendría una doble función. Por un lado, observamos cómo, ante la imposibilidad de "no sentir", el sujeto ofrece a través de la angustia una respuesta afectivoemocional al entorno (ante la incapacidad de responder adaptativamente al estímulo externo competente que activaría determinada emoción invalidada).

Por otro lado, a través de la angustia se salvaguarda la integridad del Self, pues ante la fragmentación provocada por la disociación de la experiencia emocional, la angustia articula la posibilidad de mantener la coherencia en la continuidad temporal y contextual. No obstante, aunque tenga una función adaptativa, podemos reconocer, a través de esa descripción de emoción "desagradable", que puede resultar disfuncional. ¿Por qué afirmo que, aunque cumpla una función adaptativa para la supervivencia y la integridad del Self, puede resultar "disfuncional"? Pensemos en la capacidad reflexiva o de mentalización del sujeto (Fonagy, 2016). Probablemente nos encontremos con un sujeto con incapacidad de "sentir" y "experimentar" determinadas emociones invalidadas, al que le costará reconocerlas en sí mismo y en los demás, y también mentalizar el polo afectivo en situaciones que evoquen determinadas emociones en sí mismo y en el otro, "emociones desreguladas, abrumadoras y no equilibradas por la cognición que acaban dominando la conducta" (Fonagy, 2016, p.89).

Es probable que ante tales situaciones invalidantes, que generan angustia como única respuesta afectiva posible, se dará una regresión al modo pre-mentalizador de simulación dado que las "ideas no tienden un puente entre la realidad externa y la realidad interna. Recordemos que la angustia no responde a un estímulo externo competente, sino que es "vivenciada sin objeto, indeterminada y flotante" (Kierkegaard citado de Martínez, 2017, p.26)). "El mundo mental se halla desgajado de la realidad exterior" (Fonagy, 2016, p.49); y se observa: "falta de reflexión en la acción, dado que no hay representación de la mente del otro y se produce la desidentificación afectiva con la experiencia de los demás" (Bromberg, 2016, p.108). Sugiero que también se daría una desidentificación con la experiencia propia, lo que comprenderíamos como la disociación del contenido afectivo. 
Estas "interferencias" van a moldear el sentido del Self, "hasta que nuevas experiencias emocionales conduzcan a la persona a imaginar y esperar nuevas formas de conexión emocional" (Orange, Atwood y Stolorow, 2012, p.38), señalando la necesidad de poner el foco en el "inconsciente invalidado" (Stolorow y Atwood, 1992) o, como Stern D. (2013) denomina "La experiencia no formulada", y favoreciendo un escenario donde vivir "experiencias emocionales contenedoras y validantes" (Estalayo, Rodríguez y Romero, 2009) merced a la disposición emocional entre los participantes de la relación terapéutica.

\section{LA CIRCULARIDAD RESTAURATIVA DE LA ANGUSTIA}

La angustia, por tanto, como emergente de la invalidación de la experiencia emocional, aparece como respuesta a la desregulación o invalidación contextuales de tales experiencias emocionales. Emociones que no tuvieron, ni tienen, el eco adecuado o una respuesta suficientemente sensible por parte del entorno como para integrarlas en el Self y regularlas, tanto en la experiencia interna como en la expresión de las mismas en el campo interpersonal.

Considero especialmente importante co-crear una atmosfera de reciprocidad con estos pacientes que les permita compartir el secreto, la emoción subyacente a la experiencia de la angustia, en un ambiente seguro. Esto será necesario, aunque no suficiente, pues además habría que añadir la necesidad de "no reciprocar", es decir, no reproducir experiencias pasadas traumáticas que encapsularon el secreto, el cual retorna inundando la experiencia y aniquilando al propio Self. La posibilidad de generar "una atmosfera de reciprocidad y mutualidad sin reciprocar" permitiría la posibilidad de desplegar el secreto desde la confianza de exploración del mismo, en una relación diferencial basada en un vínculo de apego seguro, de contención de aspectos transferenciales externalizados y validación del contenido privado no compartido, seguramente invalidado en etapas tempranas del desarrollo.

Para que se desarrolle este proceso es necesario partir del sentimiento de seguridad del yo, que permita afrontar los peligros y las alertas, suficientemente seguro, desde una relación construida en base a la contención y la validación. Todo ello contemplado desde el cumplimiento de algunas condiciones que predisponen al enfrentamiento/confrontación con la ansiedad que activa procesos de huida y permite abordar el estímulo, externo o interno, que la activa.

Por una parte, si las ansiedades provienen de los duelos y las pérdidas, de lo infantil que ya no tienes, y si se generan unas defensas frente a esas ansiedades que pueden invadir todo el Yo de la personalidad, con tendencias regresivas o con tendencias hacia el narcisismo que niegan las pérdidas. Por otra parte, las ansiedades pueden provenir del proceso de adquisición de lo nuevo, generando también unas defensas como el paso al acto frente a la dificultad de esperar. 
$Y$ estos dos grupos de ansiedades pueden generar respuestas fóbicas: la claustrofobia como proyección de la ansiedad de quedarse atrapado en la infancia y la agorafobia como proyección del temor de quedar desprotegido. Por eso la valoración del origen de la ansiedad es muy importante si proviene de las pérdidas o de la adquisición de lo nuevo, para entender las defensas, es decir, los sintomas". (Entrevista a Luis Feduchi, citado en Tió, Mauri y Raventós, 2014. p. 60)

En este sentido, además de valorar el origen de las motivaciones ansiógenas, deberíamos tener en consideración los movimientos progresivos o regresivos que responden a la experiencia de determinadas angustias, homeostáticas, claustrofóbicas o de estancamiento (relacionadas con el miedo a quedarse atrapado sin posibilidad de cambio) y alostáticas, agorafóbicas o de crecimiento (relacionados con la angustia que provoca el propio cambio). Las cuales dan lugar a determinadas posiciones del sujeto ante el estímulo que las activa, fóbicas o contrafóbicas que, a mi parecer, serían cuatro:

1. Posición fóbica reactiva

2. Posición fóbica depresiva

3. Posición contrafóbica exploratoria

4. Posición contrafóbica confirmatoria

Estas posiciones se distribuyen según el cuadro siguiente:

\section{Comportamiento progresivo}

\begin{tabular}{c|c}
\multicolumn{1}{c|}{$\begin{array}{c}\text { Posición fóbica } \\
\text { Reactiva }\end{array}$} & $\begin{array}{c}\text { Posición Contrafóbica } \\
\text { Ensiedades }\end{array}$ \\
\cline { 2 - 2 } $\begin{array}{c}\text { de estancamiento } \\
\text { (Claustrofóbicas) }\end{array}$ & $\begin{array}{c}\text { Ansiedades } \\
\text { de crecimiento } \\
\text { (Agorafóbicas) }\end{array}$ \\
Posición Contrafóbica & Posición Fóbica \\
Confirmatoria & Depresiva \\
&
\end{tabular}

\section{Comportamiento regresivo}

Cuadro 1 
Cada posición respondería a un comportamiento determinado ante la angustia vivida, entendiendo dos tipos de angustia principales, aquellas relacionadas con el miedo ante el crecimiento y el cambio, ansiedades propiamente agorafóbicas, y aquellas relacionadas con el miedo a quedarse atrapado, ansiedades claustrofóbicas (Tió, Mauri y Raventós, 2014).

Mientras que el comportamiento progresivo iría encaminado a explorar alternativas a la experiencia conocida, como respuesta a la angustia vivida, el comportamiento regresivo promovería actuaciones repetitivas, las cuales remiten a experiencias tempranas. No obstante, es preciso indicar que este cuadro no deja de ser una aproximación extremadamente causal y lineal, desde una perspectiva intrapersonal, cuando el enfoque relacional exige pensar en términos de circularidad, de bidireccionalidad y mutualidad relacional, dado que cualquier actitud en el paciente provoca una respuesta contra-afectiva en el profesional quien, a su vez, dependiendo de su respuesta y de la posición que adquiere frente a la experiencia del paciente, va a provocar un impacto en el mismo que favorecerá o dificultará, precisamente, su actitud ante la vivencia de la angustia y la búsqueda de alternativas de cambio que faciliten el tránsito madurativo

A mi entender, todas estas posiciones del sujeto demandan un tipo de respuesta y actitud determinada en la relación por parte del profesional, quien busca favorecer un espacio de cambio para el paciente, generando un ambiente de confianza, suficientemente seguro para que el sujeto aproveche la experiencia relacional para afrontar sus propias angustias, y así las integre y supere para un adecuado desarrollo personal.

Por "posición del terapeuta", entiendo la forma en que se articula la función del mismo en la relación terapéutica. Bion (2000), por ejemplo, afirma que: "el término "función" es usado como el nombre para un conjunto de acciones, físicas o mentales, gobernadas por o dirigidas hacia un propósito" (p. 27). Es en este sentido al que me quiero referir con el término "posición" del profesional, para hacer mención de la función del mismo en relación con un estado del Self determinado del paciente, el lugar en el que ambos se sitúan (por eso se denomina "posición"), dentro del espacio interpersonal con objeto de co-construir un proceso madurativo. Habría que indagar, por tanto, qué posibles posiciones del profesional, podrían relacionarse con cada posición del sujeto, de cara a promover procesos de cambio, ya sea una actitud fóbica o contrafóbica, según el comportamiento regresivo o progresivo, ante la amenaza de angustia de crecimiento o de estancamiento.

Las diversas respuestas del profesional deberían modularse en atención, por un lado, al contenido emocional compartido y, por otro, a la experiencia emocional privada no compartida (Linehan, 2003) que subyace al comportamiento expresado, de tipo, seguramente, desregulado o invalidado. De esta manera podremos generar un ambiente que valide la experiencia del 
paciente y le acompañe en la integración de la angustia y el afrontamiento de la misma, en el espacio de mutualidad intersubjetiva.

Las estrategias relacionales que propongo, vinculadas a las posiciones del paciente ante la angustia, serían las siguientes:

\section{Comportamiento progresivo}

\begin{tabular}{cc|cc} 
& Facilitación & Confirmación & \\
Ansiedades & & & $\begin{array}{c}\text { Ansiedades } \\
\text { de crecimiento } \\
\text { de estancamiento } \\
\text { (Claustrofóbicas) }\end{array}$ \\
& Confrontación & Contención & \\
& & & \\
& & &
\end{tabular}

\section{Comportamiento regresivo}

Cuadro 2

En relación a la posición "facilitadora" del terapeuta, podríamos establecer cierta semejanza con la "Zona de desarrollo próximo" de Vygotsky (1978), un espacio relacional que provee de la seguridad necesaria para explorar, desde las posibilidades y capacidades incipientes, puede que, todavía, no exploradas o no reconocidas por el propio paciente, merced a la ayuda y acompañamiento de "alguien más capaz" que favorece ese "andamiaje" conjunto, en un proceso de aprendizaje compartido.

Con posición de "confrontación" del terapeuta, me refiero a la necesidad de suscitar un sentimiento de incomodidad en el sujeto, en el sentido de generar cierta "frustración óptima" (Kohut, 2002), respecto a la repetición de patrones relacionales que, en el pasado, fueron funcionales, pero que en el contexto relacional actual " posición contrafóbica confirmatoria" del sujeto), en el aquí y ahora, se muestran disfuncionales. Habrá que confrontar dicha posición con el sujeto, de manera respetuosa y no invasiva, pero que invite al cuestionamiento de la experiencia, desde donde movilizar una actitud egosintónica hacia la experimentación con el síntoma, y para generar cierta egodistonía hacia el síntoma como tal. Así se posibilitaría una 
apertura mental del sujeto hacia la exploración de posibilidades de cambio que hasta entonces debido a cierta acomodación en la postura disfuncional - no se planteaba.

La "contención" debe entenderse en el sentido bioniano del término, en concreto como función de "reverie" (Bion, 1988), desempeñada por un agente suficientemente continente, como es la madre, para contener las identificaciones proyectivas del bebé, acompasando la integración en la experiencia de las partes proyectadas del Self, no toleradas previamente. La propia relación entre paciente y terapeuta, basada en un apego seguro, hace de continente del malestar del primero. Nos hacemos cargo de su propio sufrimiento ante la angustia agorafóbica que le impone una respuesta regresiva en el contexto situacional actual. Se produce así una complementariedad entre las proyecciones del paciente y la regulación afectiva del terapeuta, que recoge el malestar y lo retorna en la relación de modo que el sujeto lo pueda integrar en la vivencia de un Self coherente y unificado.

Podemos conceptualizar la "confirmación", desde el significado de la validación que proponen Estalayo, Rodríguez y Romero (2009) como: "la capacidad de influir alabando, valorando aquellos comportamientos que deseamos se mantengan o aparezcan, no en función del comportamiento en sí, sino de lo que representa" (pp. 122-123). Citan a Gunderson y Gabbard (2002) quienes plantean que la validación consiste en reforzar de forma activa la realidad de las percepciones de los sujetos, y en identificar la función adaptativa que desempeñan sus defensas y comportamientos.

Tras esta primera aproximación relacional a la angustia a partir de las posiciones del paciente y el analista, me gustaría retomar la propuesta de Martínez Ibáñez (2017) para el abordaje de la angustia de crecimiento, que establece 4 pasos: "Aceptación de la misma, relación con el crecimiento, calmarla sabiendo que lo que la motiva no es algo "real", y resaltar el crecimiento para que quede huella de ese ir hacia adelante en la vida" (p.149). Aunque esta propuesta parece muy acertada, en mi opinión únicamente estaría relacionada con la posición confirmatoria del profesional, que responde a una actitud progresiva y validante del sujeto frente a la angustia de crecimiento vivida. Pero este planteamiento - si tenemos en cuenta otras posiciones del sujeto frente a la angustia - solo respondería a una posibilidad de actuación, la cual, además, sería un paso previo para dar un lugar a la angustia desde donde poder profundizar en los contenidos emocionales que subyacen a la expresión de la misma.

En relación con las posiciones fóbicas o contrafóbicas del paciente, así como con las posibles posiciones restaurativas del profesional, desde un encuadre terapéutico basado en la importancia que cobra el establecimiento de la relación, la seguridad que el propio vinculo terapéutico provee para la exploración del contenido reprimido o disociado que activa la angustia, se requiere por parte del terapeuta un tipo de actitud que valide, contenga, confronte 
o facilite la experiencia del sujeto, ayudándole a explorar todo el contenido emocional que subyace al malestar experimentado, incluyendo las ansiedades que se activan en cada momento.

Como afirma Howard Bacal (2017b): El establecimiento de la relación, desde el primer encuentro, debe enmarcarse en la experiencia de ser sostenido. Hay que tener en cuenta la contención, tanto física como emocional, además de la validación - o el reconocimiento del contenido que subyace a la angustia y el malestar vivido -, dado que dos personas comparten sentimientos intensos a través del sostenimiento (Bacal, 2011). La teoría de la especificidad implica de manera esencial un proceso de descubrimiento de respuestas que pueden ser efectivas terapéuticamente para un paciente particular (Bacal, 2015). Toda posibilidad terapéutica dependerá, en principio, de la forma en que en cada momento dos personas puedan estar juntas a lo largo del tiempo con efectos terapéuticos. La finalidad terapéutica se consigue, a mi entender, comprendiendo diversos tipos de respuestas recíprocas, especificas a los patrones relacionales, dentro de la naturaleza única del proceso particular con un paciente concreto, pero en el marco de un sistema co-construido, intersubjetivo, de influencia mutua y recíproca, persiguiendo así, lo que Howard Bacal denomina el "encaje diádico" (2015) o, como lo denomina Stern (1998) "momentos de encuentro".

Por ello, sintonizo con la propuesta de la teoría de la especificidad como un tipo particular de teoría de procesos, que mantiene la utilidad de las teorías de la estructura, aunque quizás me situaría en una teoría estructural que se ajuste a cada proceso particular, concibiendo el proceso de cambio como la prioridad de tener presente la estructura y, desde ahí, focalizar en cada proceso particular la especificidad de la relación y, por tanto, del tratamiento terapéutico. Es por ello que, desde la Circularidad Dialógica Restaurativa de cada proceso, la respuesta del terapeuta debe ajustarse a la especificidad de cada paciente y, a su vez, de cada encuentro con el mismo, pero comprendiendo previamente qué hay detrás de la angustia vivida, el malestar experimentado y el comportamiento objetivo externalizado. En este sentido, el significado de la transferencia y la contratransferencia en el marco del campo intersubjetivo, "como actividad organizativa de la experiencia compartida" (Sotolorow y Atwood, 1992) debe responder al significado que para el paciente tiene cada experiencia. Ello nos exige conocer su historia personal y relacional, tipos de apego con cuidadores tempranos significativos, patrones relacionales internalizados, experiencias de lo traumático que se reactualizan en la relación presente y la necesidad de responder a la angustia del paciente y a las necesidades de objeto del Self, desde la responsividad óptima del terapeuta como objeto internalizado o, incluso, "yo auxiliar". Debemos, por tanto, construir procesos de cambio madurativo con pacientes, atendiendo a numerosas variables de su historia relacional, experiencias traumáticas que cobran significado en las relaciones actuales con agentes de referencia, así como el sufrimiento relacionado con la angustia vivida, ya sea claustro o agorafóbica, y los movimientos progresivos 
o regresivos que, por un lado, responden a dicha angustia y, por otro, configuran respuestas fóbicas o contra-fóbicas a la angustia vivida. Lo que nos exige como profesionales acompañar dichos procesos, por un lado, desde la comprensión de la estructura que subyace al síntoma, así como la especificidad de la respuesta profesional, tanto a la estructura como a la funcionalidad del síntoma y sufrimiento experimentado. Cada posición del paciente, exige una posición del profesional que acompañe esa experiencia, dependiendo de lo que muestra cada sujeto y las posibilidades que tiene de aprender de la experiencia, así como de la relación co-construida, lo que nos va a permitir abordar la angustia y su relación con el entorno de una manera ciertamente individualizada (aunque desde un marco estructural que nos oriente en la intervención).

No siempre respondemos igual ante un paciente que responda, a su vez, de la misma manera ante situaciones diferentes, pues cada situación nos exige respuestas diferentes, ni respondemos de la misma manera ante pacientes que tienden a servirse de las mismas estrategias para atender angustias similares, pues cada uno dependerá de su historia, de su capacidad para tolerar determinadas respuestas, así como de sus propios déficits. Como dice Bacal (2017):

La esencia de las contribuciones del analista a la experiencia del paciente de una relación de objeto del Self es su responsividad óptima a las experiencias del paciente... Estas incluyen la provisión y/o interpretación de una variedad de funciones verbales y no verbales de objeto de Self. También incluyen un deseo por colaborar en la tarea de trabajar a través de rupturas en la relación de objeto de Self entre los dos. Podría implicar una actitud indagadora o una silenciosa presencia no indagadora, una confirmación repetitiva o un reto confrontativo. Va a estar determinada no solo por los temas que el paciente y analista están trabajando, sino también por la fortaleza del Self del paciente y por sus niveles operativos de desarrollo logrados. (p.17)

No obstante, la contribución del analista también está determinada, no solamente por la propia relación, sino por la exigencia de proporcionar experiencias alternativas o, lo que Franz Alexander (1956) denomina "experiencias emocionales correctivas" en el marco de las propias necesidades del paciente. Todo ello desde el respeto por abordar lo que comparte el paciente al ritmo que él mismo puede sostener, así como la exploración del patrón de personalidad y relacional que muestre, atendiendo a estrategias de huida y evitación, o dependencia y sumisión ante las experiencias que provocan su ansiedad (Millon, 1999).

Pasemos a ejemplificar mediante un caso el planteamiento previamente desarrollado. 


\section{VIÑETA CLINICA}

Se trata de una paciente de 19 años, que vive actualmente en casa de la familia extensa materna, junto con su hermano pequeño de 17, debido a la ausencia de los padres, por fallecimiento de la madre y abandono del padre.

La vida de la joven está marcada por la ausencia del padre y una maternidad negligente, que desatendió las necesidades afectivas de la joven y de su hermano en etapas tempranas del desarrollo, así como posteriormente.

La paciente recuerda haber pasado largos periodos de tiempo con la tía y los abuelos maternos, recibiendo una educación autoritaria y desconfirmatoria. No les permitían mostrar tristeza por el abandono paterno y la ausencia de la madre que, de alguna manera, se vive como otro abandono. Los abuelos y la tía aplican con severidad las reglas que rigen la convivencia y sancionan duramente las expresiones de determinadas experiencias emocionales, que les incomodan y que coartan y erradican con agresividad, o incluso violencia.

No obstante, la madre está presente en sus vidas, pero de manera muy poco participativa, bastante periférica, debido a problemas con el consumo y la prostitución. La paciente reconoce sentimientos de ambivalencia hacia ella, pues asegura quererla porque "es su madre", pero la odia por todo el daño que le ha hecho.

Actualmente no estudia ni trabaja, no encuentra motivación en prepararse para el futuro, ni en la búsqueda activa de formación o empleo. Se muestra distante, ciertamente desconfiada, suspicaz, evitativa y contradependiente. Verbaliza que "no le gustan los psicólogos porque no le gusta que nadie sepa lo que esconde". Además, considera que "los profesionales pretenden hacer lo que sus padres no hicieron y nadie es mejor que ellos", a lo que se responde que nadie pretende sustituir a sus padres y que no se pretende hacer mejor las cosas.

Observo en ella cierta capacidad instrumental y manipulativa, de servirse de los demás para generar conflictos y conseguir determinados objetivos. No obstante, muestra dificultades de adaptación relacional, desde la agresividad y la violencia.

Actualmente, entre semana, invierte su tiempo en jugar con el móvil, por las mañanas metida en la cama y por las tardes en casa del novio. Los fines de semana ambos pasan el tiempo en el "ciber", jugando a juegos de rol online.

Dice pasar grandes periodos de tiempo en la cama porque no tiene nada que hacer, reconoce que tampoco le interesa. Su única motivación es la relación con su novio, quien también parece tener una red social bastante empobrecida, dado que se limita a la relación de pareja. También verbaliza depender de su familia extensa pues manifiesta "no sabe hacer nada si no es acompañada", hecho por el cual, si no hay nadie disponible, prefiere quedarse en casa, tumbada 
en la cama, jugando son el móvil. Dice que esto último lo hace "para no pensar". No pensar en la falta de los padres, en la soledad y en su sentimiento de "inutilidad".

Creo comprender el sentimiento de la paciente desde el propio miedo al sentimiento de soledad y posible vacío vivenciados. Este temor, seguramente no identificado y, por supuesto, no regulado, lo expresa a través de la irascibilidad y el desafío; desde una angustia no identificada.

Aparentemente parece experimentar cierta tristeza, aunque tampoco la manifiesta. En ocasiones llego a pensar que tal vez no sea tristeza, sino un vacío que no puede tolerar ni subsanar con las experiencias que se le presentan, resultándole complicado apropiarse de las mismas y aprovechar su calidad, por lo que muestra un falso Self que enmascara y protege un estado del Self disociado y "atormentado", que se muestra a través de la angustia.

Miro y observo a una joven reactiva ante el cambio, violenta y agresiva, impulsiva - aunque en ocasiones muestre capacidad de instrumentalidad y proactividad en su conducta violenta -, lo que podría guardar relación con la emergencia de determinadas vivencias afectivas y emocionales, invalidadas en periodos tempranos del desarrollo - como son el miedo y la tristeza -, que hieren su narcisismo, por lo que reacciona con el comportamiento agresivo y violento, desregulado y desmedido, como única solución ante la desesperación.

En conversaciones con la joven, verbaliza querer hacerse cargo de su hermano y acometer una función maternal en la dinámica familiar más amplia, cuidando y nutriendo emocional y afectivamente a sus primos pequeños. Pero esto le genera angustia pues le resulta complicado imaginarse en los términos que propone y considera que tiene que asumir. En algún momento, hablamos de la posibilidad de que el hecho de quedarse en la cama acaso responda a la necesidad de que alguien la atienda, pues los tíos con quienes convive, se muestran preocupados por su actitud desmotivada. A lo largo del tiempo que lleva viviendo con esta familia, comentan que le acompañan a hacer gestiones, matriculas a cursos que van apareciendo, pero solo consiguen que acuda si la acompañan. De alguna manera, necesita la confirmación de que alguien se hace cargo de ella, pues reconoce sentirse incompetente.

Poco a poco, vamos conteniendo esa actitud de quedarse en la cama para "ser atendida", así como su "exigencia" de ser acompañada a todos los sitios para hacer gestiones, dado que entiendo que es una actitud contrafóbica que responde, mediante un comportamiento regresivo, a su angustia de crecimiento, que expresa el miedo ante lo desconocido, miedo invalidado en su contexto relacional. A lo largo del tiempo, según comentan, va saliendo de casa por las mañanas, aunque con una actitud desafiante y provocadora, que reta al otro, buscando la confrontación constante. Ante esta nueva situación, muestro una actitud de facilitación, que le permita explorar, desde su motivación por levantarse, qué sucede y qué le provoca ansiedad, 
intentado rescatar aquellos aspectos positivos que la mueven a salir de la cama para plantearse hacer algo.

Comenta que intenta "dar el paso", pero siente que nadie la acompaña. Se siente abrumada porque considera que ella hace esfuerzos por hacer cosas, pero no hay respuesta, por parte del ambiente, que sostenga esa actitud $y$, por ello, se enfada.

Desde esa actitud facilitadora, rescatamos los aspectos positivos de la joven que se pretenden movilizar, a la vez que se confronta la actitud desafiante infantil ante la angustia de estancamiento que busca atención por parte de los adultos que la acompañan, para que le resuelvan sus propios temores relacionados con sentimientos de incapacidad.

Con la ayuda y acompañamiento de los adultos con quienes convive, poco a poco, se va animando a realizar gestiones, matriculas a cursos, aunque sean cursos de pocas horas, que le van reportando un sentimiento diferente de sí misma, una mirada ciertamente más confiada que le permite, progresivamente, explorar el entorno. Paulatinamente va dando pasos sola a la hora de gestionar su tiempo por las mañanas, al principio lo hacía acompañada, a lo largo de este tiempo, desde su espacio potencial y zona de desarrollo próximo, ella misma comienza a organizarse las mañanas, y busca trabajo mientras acude algunos días a un curso de estética. Conforme va trayendo al espacio de terapia estos avances, validamos, no solo su comportamiento progresivo (posición contrafóbica exploratoria) relacionado con su enfrentamiento a la angustia de crecimiento, sino que atendemos a todas las experiencias emocionales que subyacen a dicha ansiedad, que guardan relación con el miedo invalidado en su familia desde tiempos muy tempranos, y favorecemos un espacio donde identificarlos, regularlos y expresarlos de manera respetuosa y adaptativa.

Con este ejemplo he pretendido acercar, de alguna manera, la idea previamente propuesta como reflexión, a la vez que planteo los pasos que puede ir dando en una dirección determinada, abordando sus dificultades desde la propia relación, lo que ella deposita en la misma y lo que ella recibe de la misma, en función de lo que entendemos que subyace al malestar vivenciado. También cabe señalar cómo a lo largo de un proceso terapéutico no debemos enmarcar la relación en una u otra posición, pues a lo largo de la construcción de la relación y de diferentes momentos de cambio, se requieren posiciones diversas que respondan al momento y la vivencia de cada paciente. Por eso, a lo largo de un proceso, incluso en una misma sesión, debemos situarnos en posiciones simétricas o complementarias con la finalidad de movilizar aquellos aspectos del paciente que quedan anclados a vivencias tempranas invalidantes y traumáticas, en el sentido evolutivo del término (Bromberg, 2017). 


\section{REFERENCIAS}

Alexander, F. \& French, T. M. (1946). Psychoanalytic Therapy: Principles and applications. New York: Rounld Press.

Ávila Espada, A. (ed.) (2013). La tradición interpersonal. Perspectiva social y cultural en psicoanálisis. Madrid. Colección pensamiento relacional.

Ávila Espada, A. (2015). Del encuadre como factor técnico a la intersubjetividad del vínculo terapéutico. Clínica e Investigación Relacional. 9 (2): 394-397.

Bacal, H.A. (2017a). La Relación de Objeto del Self en el Tratamiento Psicoanalítico. Clínica e Investigación Relacional, 11 (1): 11-21.

Bacal, H.A. (2017b). La responsividad óptima y el proceso terapéutico. Clínica e Investigación Relacional, 11 (1): 22-50.

Bacal, H.A. (2017c). La especificidad de la eficacia terapéutica en el proceso psicoanalítico. Versión castellana del trabajo presentado en Madrid, Ágora Relacional-IPR, 5 y 6 Mayo de 2017.

Bacal, H.A. con Carlton, L. (2017d). Cómo la teoría de la especificidad cambia la práctica clínica (Fragmento). Versión castellana del capítulo 3 de Ibid. The Power of Specificity in Psychotherapy. When therapy works and when it doesn't (Lanham, MD: Jason Aronson, 2011).

Bacal, H.A. (2017e). Más allá de la Transferencia y contratransferencia: La especificidad diádica del proceso psicoanalítico. Versión castellana del trabajo presentado en la 38th Annual IAPSP International Conference Los Angeles, California, October 17, 2015.

Bateson, G. (1972). Steps to a n ecology of mind. New York: Ballantine.

Bateson, G. (1979). Mind and nature: A necessary unity. New York: Dutton.

Bion, W. (1962). Learning from Experience. London: Heinemann.

Bion, W. (2000) Elementos de psicoanálisis, Lumen-Hormé, Buenos Aires.

Bowlby, J. (1969). Attachment and loss. I. Attachment. London. The Hogarth Press.

Bromberg, P. (2017). La sombra del Tsunami y el desarrollo de la mente relacional. Madrid. Colección pensamiento relacional.

Damasio, A. (1995). El error de Descartes. Barcelona. Ed. Destino.

Estalayo, A., Rodriguez, O., y Romero, J.C. (2009). Estilos de crianza y ambientes familiares en menores y jóvenes violentos. Un modelo de psicotearpia de apoyo para la intervención. Cuadernos de psiquiatría y psicoterapia del niño y del adolescente. (48) 113-129.

Estalayo, A., Rodríguez, O. y Gutiérrez, R. (2016). El encuadre en contextos de intervención convivencial de protección de menores y justicia juvenil. Intervención psicoterapéutica en instituciones. Cuadernos de psiquiatría y psicoterapia del niño y del adolescente. (62), 33-43.

Fenichel, O. (1939). La actitud contra-fóbica. En Jorge J. Saurí (comp.) (1976) Las Fobias. Buenos Aires: Nueva Visión.

Fonagy, P., y Bateman, A. (2016). Tratamiento basado en la mentalización para trastornos de la personalidad. Una guía práctica. Bilbao. Desclée de Brouwer. 
Greenberg, L. (2000). Emociones: Una guía interna. Bilbao. Desclée De Brouwer.

Greenberg, L. y Paivio, S., 2000. Trabajar con las emociones en psicoterapia. Barcelona. Paidós.

Greenberg, J. (1995). Psychoanalytic technique and the interactive matrix. Psychoanalytic Quarterly, (63), 1-22.

Gunderson, J. G. y Gabbard, G. O. (2002), Psicoterapia en los trastornos de personalidad, Barcelona, Ars Médica.

Khan, M. M. R. (1963). The concept of cumulative trauma. The psychoanalytic study of the child, 18(1), 286-306

Khan, M. (1983/1991). Locura y Soledad. Entre la teoría y la práctica psicoanalítica. Buenos Aires.

Kohut, H. (2002). Los dos análisis del sr. Z. Barcelona. Herder.

Linehan, M. (2003). Manual de tratamiento de los trastornos de la personalidad límite. Barcelona. Paidós.

Marrone, M. (2001). La teoría del apego. Un enfoque actual. Madrid. Psimática.

Martínez, J.J., (2017). El enigma de la angustia. Una conceptualización de la angustia desde el vértice relacional. Madrid. Colección pensamiento relacional.

Millon, T., Davis, R.D., Millon, C. Wenger, A., van Zuilen, M.H., Fuchs, M. y Millon, R.B. (1999). Trastornos de la Personalidad. Más allá del DSM-IV. Barcelona: Masson.

Orange, D.M.; Atwood, G.E.; Stolorow, R.D. (2012). Trabajando intersubjetivamente. Contextualismo en la práctica psicodinámica. Madrid. Ágora Relacional. Colección pensamiento relacional nº6.

Palazzoli Selvini, M., Boscolo, L., Cecchin, G., \& Prata, G. (1980). Hypothesizing-circularityneutrality: Three guidelines for the conductor of the session. Family Process, 19,3-12.

Stern, D. Sandler, L., Harrison, A., Lyons-Ruth, K. Morgan, A. Bruschweilerstern and Tronick, E. (1998). Non-interpretive mechanisms in psychoanalytic therapy: The 'Something More' than interpretation. Int . J. psychoanal. 79:903-921.

Stern, D.B. (2013). La experiencia no formulada. Del caos conocido al desorden creativo. Cap. 10 de la obra de A. Ávila Espada (Ed.): La tradición interpersonal. Perspectiva social y cultural en psicoanálisis. Madrid: Ágora Relacional

Stolorow, R. y Atwood, G (1992). Los contextos del ser. Barcelona. Herder.

Tió, J, Mauri, L. y Raventós, P. (2014). Adolescencia y trasgresión. La experiencia del Equipo de Atención Mental al Menor (EAM). Barcelona. Ediciones Octaedro, S.L.

Vygotsky, L.S. (1978). Mind in Society. Cambridge, MA: Harvard University Press.

Watzlawick, P., Beavin, J. y Jackson D., (1981). Teoría de la comunicación humana. Interacciones, patologías y paradojas. Barcelona. Herder.

Winnicott, D. W. (1979). Escritos de pediatría y psicoanálisis. Barcelona. Paidós.

Original recibido con fecha: 16/11/2017 Revisado: 26/1/2018 Aceptado: 28/02/2018 